\title{
Individual and Relationship-Level Correlates of Transactional Sex Among Adolescent Girls and Young Women in Malawi: A Multilevel Analysis
}

\author{
Margaret W. Gichane ${ }^{1,2}$ (D) Nora E. Rosenberg ${ }^{1,3} \cdot$ Catherine Zimmer $^{4} \cdot$ Audrey E. Pettifor $^{5} \cdot$ Suzanne Maman ${ }^{1}$. \\ Bertha Maseko ${ }^{3} \cdot$ Kathryn E. Moracco ${ }^{1}$
}

Accepted: 14 August 2021 / Published online: 23 August 2021

(c) The Author(s) 2021

\begin{abstract}
Transactional sex increases HIV risk among adolescent girls and young women (AGYW). Understanding the individual and dyadic nature of transactional sex may provide evidence for risk reduction interventions. Multilevel logistic regression was used to cross-sectionally examine correlates of transactional sex among AGYW in Lilongwe, Malawi. Participants $(\mathrm{N}=920)$ reported 1227 relationships. Individual-level associations were found between being divorced/widowed (AOR 5.07, 95\% CI $1.93,13.25$ ), married (AOR 0.26, 95\% CI 0.09, 0.72), or unstably housed (AOR 7.11, 95\% CI 2.74, 18.47) and transactional sex. At the relationship-level, transactional sex occurred in relationships with: non-primary primary partners (AOR 4.06, 95\% CI 2.37, 6.94), perceived partner concurrency (AOR 1.85, 95\% CI 1.11, 3.08), and feared violence with couples HIV testing (AOR 2.81, 95\% CI 1.26, 6.29), and less likely to occur in relationships with children (AOR 0.15, 95\% CI 0.06, 0.38). Multiple co-occurring social and structural vulnerabilities increase transactional sex engagement warranting the need for social protection and gender transformative approaches.
\end{abstract}

Keywords Transactional sex $\cdot$ Adolescent girls $\cdot$ Young women $\cdot$ Partners $\cdot$ Multilevel

Margaret W. Gichane

margaret.gichane@ucsf.edu

1 Department of Health Behavior, Gillings School of Public Health, University of North Carolina at Chapel Hill, Chapel Hill, NC, USA

2 Present Address: Department of Obstetrics, Gynecology $\&$ Reproductive Sciences, Advancing New Standards in Reproductive Health, University of California, San Francisco, Oakland, CA, USA

3 UNC Project, University of North Carolina at Chapel Hill, Lilongwe, Malawi

4 HW Odum Institute for Research in Social Science, University of North Carolina at Chapel Hill, Chapel Hill, NC, USA

5 Department of Epidemiology, Gillings School of Public Health, University of North Carolina at Chapel Hill, Chapel Hill, NC, USA

\section{Introduction}

Adolescent girls and young women (AGYW) in sub-Saharan Africa (SSA) are a population at increased risk of HIV infection. AGYW ages 15-24 years old account for a quarter of new HIV infections in the region [1]. Transactional sex, defined as, "noncommercial, nonmarital sexual relationships motivated by an implicit assumption that sex will be exchanged for material support or other benefits [2,3]," increases AGYW's risk of acquiring HIV [4, 5]. Understanding the nature of transactional sex may allow us to reduce the risk within these relationships, which may in turn have an impact on HIV transmission rates among AGYW.

Studies of transactional sex in Malawi show the frequency and complexity of the behavior across a variety of settings [6-9]. Male provision of gifts to their female partners is integral role to the quality and duration of relationships of young rural Malawians. Gifts and money symbolize trust, demonstrate love, confer social status, and display gendered expectations of males as providers. Within relationships, the value of the item a girl receives may indicate her value to her partner. Further, couples report negotiating exchanges 
to retain their relationship [6]. Youth living in urban slums in Blantyre describe transactional sex as a common practice that is a product of material depravation that young people face in their communities. In particular, transactional sex is seen as a method to acquire money or goods in response to, unstable or poor housing conditions, food insecurity, and limited access to medical treatment. However, for young women, transactional sex is also seen as a tool that they can use to their advantage in different situations, and that can be used to acquire consumer goods [8]. Most evidence about exchange in transactional relationships comes from qualitative studies, which are limited in their generalizability. Systematically quantifying who is engaged in transactional relationships, what is exchanged, and distinguishing these features from non-transactional relationships, may provide critical insights about AGYW's motivations to engage in these relationships and ultimately make them safer.

To date, studies of transactional sex have primarily focused on the characteristics of AGYW who engage in the behavior, ignoring characteristics of the relationships. Socioeconomic characteristics such as food insecurity [10, 11-13], housing $[10,11]$, orphan status $[14,15]$, education $[10,11$, $13]$, and household wealth [11, 12] increase AGYW's likelihood of engaging in transactional sex. Among the studies that have examined partner characteristics, age differences between partners have received the most attention [16-18]. Relationships in which there is a substantial age-difference ( $\geq 5$ years or $\geq 10$ years) between partners are often transactional [16-18]. Additionally, relationships which are characterized by partner concurrency [18] or violence [19], as well as those which are more casual [20,21], are more likely be transactional.

Examining individual and relationship characteristics concurrently may lead to more comprehensive insights surrounding transactional sex, and potential interventions to make transactional relationships safer for AGYW. Multilevel modeling (MLM) is a rigorous analytical approach well suited to examine how factors at both the individual and relationship level are associated with a particular outcome [22]. MLM has been used widely to examine how individual demographics and partner traits predict risky encounterlevel sexual behaviors such as condom use [23, 24]. MLM accounts for the hierarchal structure of data which permits the examination of multiple partnerships within the same person. One of the benefits of this approach is that it can assess whether individual-level characteristics (e.g., food insecurity, housing) and relationship characteristics (e.g. age difference, partner type) are robust predictors of behaviors across partnerships [25].

The purpose of this study is to characterize AGYW's transactional sexual relationships. Specifically, we seek to: (1) describe and compare the gifts and material support received from transactional and non-transactional partners; and (2) examine the separate and combined associations between individual-level and relationship-level characteristics, and transactional sex engagement.

\section{Methods}

\section{Study Design and Population}

Data for this analysis were from the baseline assessment of Girl Power-Malawi, a quasi-experimental prospective cohort study conducted in four public-sector clinics Lilongwe, Malawi from February 2016-August 2017. Girl PowerMalawi Participants were recruited and enrolled in one of four models of care including: the standard of care, youth friendly health services (YFHS), YFHS and a 12 session group-based behavioral intervention, and the former along with a conditional cash transfer (CCT) based on attendance to behavioral intervention (BI) sessions. More detailed information about the study design and main findings are published elsewhere [26-28].

Two-hundred and fifty participants were recruited from each of the four clinics via community outreach activities, chain-referral from current study participants, and self-referral $(\mathrm{N}=1000$ total). Eligibility criteria included: age in the 15-24-year range, residence in proximity to the study clinic, and willingness to enroll in the study for a 1-year period.

Interviews were conducted in Chichewa by trained female research assistants. Data were captured using Open Data Kit (ODK) software on Android tablets. A baseline behavioral survey covered participant's demographic information, sexual and reproductive behavior, and healthcare-seeking patterns. Participants were also asked to report information on their recent sexual partners in a partner grid. For each partner, participants were asked to report on characteristics of the relationship.

The following analyses use baseline behavioral survey to examine cross-sectional relationships between individual and relationship-level characteristics and transactional sex engagement. To examine these relationships, a relationship dataset was created with each individual line representing a different partner from the partner grid. Each participant could contribute information on up to three of their most recent relationships. Analysis was restricted to relationships which occurred in the last 6 months, thus, participants with no self-reported partnerships within the 6 months preceding baseline were excluded. Time period was assessed based on self-reported number of months since last intercourse with the partner. 


\section{Measures}

\section{Descriptive Variables}

Type and magnitude of material and monetary support were assessed for all partners. For material support, participants provided information on whether they received any of the following nine items: airtime, cell phone or other electronics, food, clothes or shoes, cosmetics (perfume, lotions, makeup), beauty treatments (hair, nails, braiding, etc.), music or videos, alcohol, and drugs. For material support, participants were asked how much money they received from partners and the frequency in which they received it.

\section{Dependent Variables}

The primary outcome of interest, "transactional sex," was measured at the relationship-level. Transactional sex was a dichotomous outcome assessed by combining responses to two different measures. The first, was "Have you ever felt like you had to have sex with this partner because he gave you money or other things?" Response options were "yes," "no," and "do not know." The second was, "What is the main reason you are with this partner?" Response options included: (1) looks/physical attraction; (2) love/romance/ emotional support; (3) money/gifts/financial support; (4) adventure/entertainment; (5) status among friends; (6) family pressure; (7): do not know. Relationships were considered transactional if there was an affirmative response to the first question or if "money/gifts/financial support" was selected as the primary motivator in the second question. All marital relationships were considered non-transactional even if either two items designated the partner as transactional based on recent definitions of transactional sex [3, 29].

\section{Independent Variables}

The independent variables of interest were measured at the participant level as well as the relationship level. Participant level socioeconomic status (SES) variables refer to demographic information and the resources a participant or their household possess. The SES factors examined included: marital status, educational attainment, orphan status, food insecurity, unstable housing, savings, employment, running water, floor type, electricity, and asset index. Relationship level factors pertain to the characteristics of the partnership. The relationship-level factors include the age difference between the participant and partner, primary or non-primary relationship, marital relationship with participant, cohabitation with the participant, children with the participant, Whether the female participant perceived that her partner had concurrent partners during the past 6 months, ever tested for HIV as a couple with the participant, fear violence if tested with the participant, and fear abandonment if tested with the participant. All relationship-level variables were reported by the female participant.

\section{Covariates}

Participant age was included a priori as a covariate as it is a potential confounder of the relationship between SES and sexual behavior. Also, given that participants were recruited from four clinics, dummy variables for clinic were constructed to account for any differences attributed to the settings they were recruited from.

\section{Analyses}

We began by reporting univariate socioeconomic characteristics of the sample using frequencies and percentages. We then used the relationship dataset to assess the characteristics of AGYW's reported relationships. Next, we calculated material and monetary support associated with each relationship. For material support, we examined differences in the proportion of participants who reported receiving each of the nine gifts based on whether the partner was transactional or non-transactional using Pearson chi-squared tests. For monetary support, we calculated medians, IQRs, and two-sample t-tests comparing the monthly amount of money received from transactional versus non-transactional partners.

To examine individual and partner level factors associated with transactional sex, we used multilevel modeling (MLM) as an analytical approach. MLM was selected to account for the nesting of partners (Level 1) within each individual AGYW (Level 2). We ran bivariate and multivariable mixed effects logistic regression using Stata 15 (College Station, TX). We first fit separate bivariate mixed effects logistic regression models with each individual level and partner level factor and transactional sex. Next, we ran three multivariable mixed effects logistic regression models to examine the separate and combined relationships between individual and relationship-level factors and transactional sex. Model 1 included all individual level characteristics. Model 2 included all partner level characteristics. In Model 3, the final model, we entered all individual and partner level characteristics that were significant at $p<0.20$ in the individual models and removed variables using a backward elimination procedure, retaining factors which were significant at $\mathrm{p}<0.05$. All three models controlled for age and clinic. All models used a logit link and binomial distribution to estimate odds ratios and $95 \%$ confidence intervals.

\section{Ethics}

Prior to participation, consent was obtained from participants 18-24 years old, and assent and consent from a parent, 
guardian, or authorized adult were obtained for participants 15-17. The study was approved by the University of North Carolina Institutional Review Board and Malawi National Health Sciences Research Committee.

\section{Results}

\section{Sample and Relationship Characteristics}

One thousand participants were interviewed at baseline. Among them, 65 (7\%) reported not having any sexual relationships within the past 6 months and $15(2 \%)$ did not respond to key questions assessing transactional sex. Thus, the analyses included 920 AGYW (Table 1). The median age in the sample was 17 (IQR 15-21). The majority of participants were unmarried (70\%). Twenty-three percent were married, and seven percent were divorced or widowed. Most had completed primary school (70\%) and had two living parents $(65 \%)$. Food insecurity was fairly common in this sample with over a third of participants reporting going to bed hungry on 1 or more days in the past month. A few AGYW reported being unstably housed (7\%). Over half of participants (54\%) were unemployed and the rest were enrolled as students (28\%) or working for pay/self-employed (15\%). Most lived in homes with no running water (58\%) or electricity (63\%). About one third (31\%) had earth/sand floors in their homes and $40 \%$ had two of fewer assets.

These 920 participants reported a total of 1247 relationships in the past 6 months. Of these 920 participants, $74 \%$ reported one partner, $18 \%$ reported two partners, and $8 \%$ reported three or more partners. Outcome data were missing for 20 relationships, making the total partner sample 1227 (Table 2). The age difference in the majority of relationships was less than 10 years (89\%) and most were primary relationships (78\%) (Table 2). Of reported relationships, few were marriages (16\%), or included children together (19\%) or cohabitation (15\%). The majority (55\%) of relationships had lasted longer than 6 months. Twenty-six percent of partners had been tested for HIV with the participant as a couple. Fear of physical violence or abandonment prevented AGYW from seeking couple's HIV testing with $8 \%$ and $12 \%$ of partners, respectively.

Twenty-two percent of relationships were transactional.

\section{Material and Monetary Support}

AGYW were more likely to receive gifts from non-transactional versus transactional partners ( $61 \%$ vs. $55 \%, \mathrm{p}=0.042)$. The top three items received from partners was the same across partner type and included food, clothes or shoes, and cosmetics (Fig. 1). Out of the nine items listed, AGYW received an average of 1.9 items (SD 2.4) from transactional
Table 1 Demographic characteristics $(\mathrm{N}=920)$

\begin{tabular}{|c|c|c|}
\hline & $\mathrm{n}$ & $\%$ \\
\hline \multicolumn{3}{|l|}{ Age } \\
\hline $15-19$ & 529 & $58 \%$ \\
\hline $20-24$ & 321 & $35 \%$ \\
\hline \multicolumn{3}{|l|}{ Marital status } \\
\hline Single & 646 & $70 \%$ \\
\hline Married & 209 & $23 \%$ \\
\hline Divorced/widowed & 64 & $7 \%$ \\
\hline Missing & 1 & $0 \%$ \\
\hline \multicolumn{3}{|l|}{ Education level } \\
\hline Did not complete primary & 266 & $29 \%$ \\
\hline Completed & 646 & $70 \%$ \\
\hline Missing & 8 & $1 \%$ \\
\hline \multicolumn{3}{|l|}{ Orphanhood } \\
\hline Both parents alive & 597 & $65 \%$ \\
\hline Single orphan & 244 & $27 \%$ \\
\hline Double orphan & 79 & $9 \%$ \\
\hline \multicolumn{3}{|l|}{ Experienced any food insecurity } \\
\hline No & 606 & $66 \%$ \\
\hline Yes & 314 & $34 \%$ \\
\hline \multicolumn{3}{|l|}{ Unstably housed } \\
\hline No & 854 & $93 \%$ \\
\hline Yes & 66 & $7 \%$ \\
\hline \multicolumn{3}{|l|}{ Have savings } \\
\hline No & 821 & $89 \%$ \\
\hline Yes & 96 & $10 \%$ \\
\hline Missing & 3 & $0 \%$ \\
\hline \multicolumn{3}{|l|}{ Employment } \\
\hline Unemployed/other & 495 & $54 \%$ \\
\hline Full-time student & 256 & $28 \%$ \\
\hline Working for pay/self-employed & 160 & $17 \%$ \\
\hline Missing & 9 & $1 \%$ \\
\hline \multicolumn{3}{|l|}{ Household socioeconomic factors } \\
\hline \multicolumn{3}{|l|}{ Running water in home } \\
\hline No & 529 & $58 \%$ \\
\hline Yes & 391 & $43 \%$ \\
\hline \multicolumn{3}{|l|}{ Housing material } \\
\hline Earth or sand & 284 & $31 \%$ \\
\hline Cement/tile/other & 635 & $69 \%$ \\
\hline Missing & 1 & $0 \%$ \\
\hline \multicolumn{3}{|l|}{ Electricity in home } \\
\hline No & 577 & $63 \%$ \\
\hline Yes & 341 & $37 \%$ \\
\hline Missing & 2 & $0 \%$ \\
\hline \multicolumn{3}{|l|}{ Asset Index } \\
\hline$\leq 2$ assets & 367 & $40 \%$ \\
\hline$\geq 3$ assets & 553 & $60 \%$ \\
\hline
\end{tabular}


Table 2 Relationship characteristics and sexual risk factors $(n=1227)$

\begin{tabular}{|c|c|c|}
\hline & $\mathrm{n}$ & $\%$ \\
\hline \multicolumn{3}{|l|}{ Relationship characteristics } \\
\hline \multicolumn{3}{|l|}{ Intergenerational } \\
\hline$<10$ years age difference & 1097 & $89 \%$ \\
\hline$\geq 10$ years older & 57 & $5 \%$ \\
\hline Unknown partner age & 73 & $6 \%$ \\
\hline \multicolumn{3}{|l|}{ Relationship type } \\
\hline Primary & 958 & $78 \%$ \\
\hline Non-primary & 267 & $22 \%$ \\
\hline \multicolumn{3}{|l|}{ Children together } \\
\hline No & 990 & $81 \%$ \\
\hline Yes & 234 & $19 \%$ \\
\hline Missing & 3 & $0 \%$ \\
\hline \multicolumn{3}{|l|}{ Cohabitate } \\
\hline No & 1038 & $85 \%$ \\
\hline Yes & 189 & $15 \%$ \\
\hline \multicolumn{3}{|l|}{ Sexual concurrency } \\
\hline No & 581 & $47 \%$ \\
\hline Yes/don't Know & 643 & $52 \%$ \\
\hline Missing & 3 & $0 \%$ \\
\hline \multicolumn{3}{|l|}{ Relationship length } \\
\hline 1 day & 161 & $13 \%$ \\
\hline$<6$ months & 378 & $31 \%$ \\
\hline$\geq 6$ months & 675 & $55 \%$ \\
\hline Missing & 13 & $1 \%$ \\
\hline \multicolumn{3}{|l|}{ Couples HIV testing } \\
\hline Have not been tested as couple & 906 & $74 \%$ \\
\hline Have been tested as a couple & 316 & $26 \%$ \\
\hline Missing & 5 & $0 \%$ \\
\hline \multicolumn{3}{|c|}{ Fear physical violence if tested together } \\
\hline No/have tested as a couple & 1106 & $90 \%$ \\
\hline Yes & 94 & $8 \%$ \\
\hline Missing & 27 & $2 \%$ \\
\hline \multicolumn{3}{|l|}{ Fear abandonment if tested together } \\
\hline No/have tested as a couple & 1039 & $85 \%$ \\
\hline Yes & 153 & $12 \%$ \\
\hline Missing & 35 & $3 \%$ \\
\hline
\end{tabular}

partners and 2.2 items (SD 2.4) from non-transactional partners.

In contrast, more transactional partners (96\%) compared to non-transactional partners $(85 \%)$ provided money $(\mathrm{p}<0.001)$. Of the 1074 partnerships where money was provided, transactional partners provided more money compared to non-transactional partners. The median amount provided was $\$ 8.28$ (IQR \$4.14-16.55) from transactional partners and \$6.90 (IQR \$2.76-13.79) for non-transactional partners. T-tests comparing the mean amount provided by partners, indicated that AGYW tend to receive more from transactional partners $(\mathrm{M}=\$ 15.85$, SD $\$ 20.05)$, compared to non-transactional partners $(\mathrm{M}=\$ 13.50, \mathrm{SD} \$ 21.19)$, though findings were marginally significant $(\mathrm{p}=0.06)$.

\section{Individual-Level Factors Associated with Transactional Sex}

Several individual level factors were associated with transactional sex. In bivariate analyses, being divorced, being a double orphan, being unstably housed, living in a home without running water, and having few household assets were associated with transactional sex. After adjusting for all individual level factors, age, and clinic, there was some attenuation among factors associated with transactional sex (Table 3, Model 1). Being divorced or widowed (AOR 4.94, 95\% CI 1.85, 13.19), married (AOR 0.08, 95\% CI $0.03,0.23$ ), a double orphan (AOR 1.86; 95\% CI 0.73, 4.76), unstably housed (AOR 4.65, 95\% CI 1.80, 11.99), unemployed (AOR 2.26, 95\% CI 0.95, 5.42), as well as having no savings (AOR 0.52, 95\% CI 0.22, 1.24), or living in a home with earth/sand flooring (AOR 0.50, 95\% CI 0.23, 0.88), and having fewer assets (AOR 1.59, 95\% CI 0.81, 3.13) met the cut-off point of $<0.20$ for inclusion in model three.
Fig. 1 Items received from transactional vs. non-transactional partners

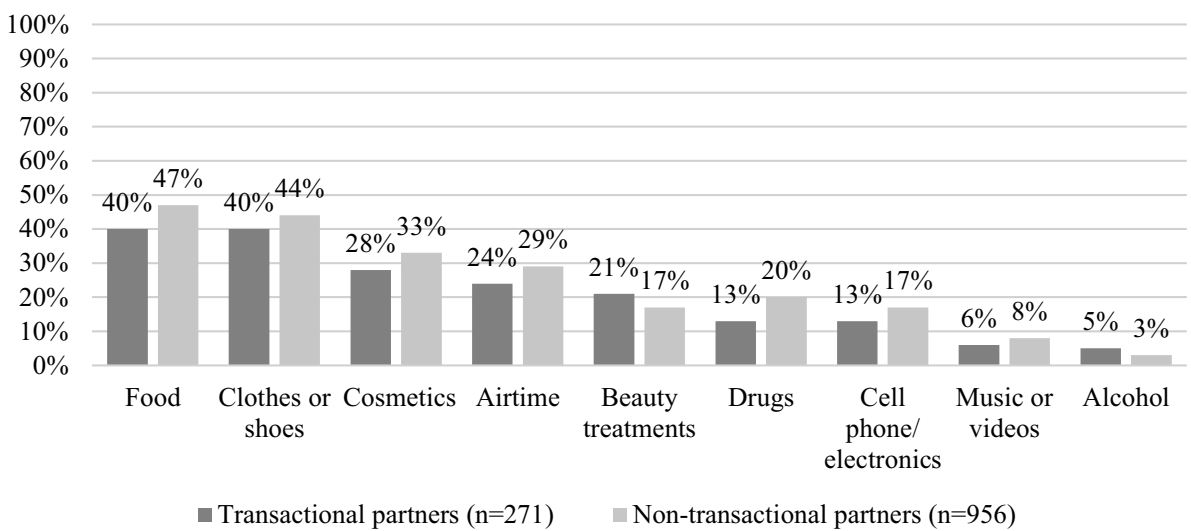


Table 3 Multilevel logistic regression of individual and partner level correlates of transactional sex

\begin{tabular}{|c|c|c|c|c|c|c|}
\hline \multirow[t]{2}{*}{ Individual } & \multicolumn{2}{|c|}{ Model 1: individual } & \multicolumn{2}{|c|}{ Model 2: partner } & \multicolumn{2}{|c|}{ Model 3: combined } \\
\hline & AOR & $95 \% \mathrm{CI}$ & AOR & $95 \% \mathrm{CI}$ & AOR & $95 \% \mathrm{CI}$ \\
\hline \multicolumn{7}{|c|}{ Individual Socioeconomic factors } \\
\hline \multicolumn{7}{|l|}{ Marital status ( $\mathrm{ref}=$ single $)$} \\
\hline Single & Ref & & & & Ref & \\
\hline Married & $0.08 * * *$ & $(0.03,0.23)$ & & & $0.26^{* *}$ & $(0.09,0.72)$ \\
\hline Divorced/widowed & $4.94 * *$ & $(1.85,13.19)$ & & & $5.07 * *$ & $(1.93,13.25)$ \\
\hline \multicolumn{7}{|l|}{ Educational attainment } \\
\hline Primary school or higher & Ref & & & & & \\
\hline Less than primary school & 1.16 & $(0.60,2.28)$ & & & - & - \\
\hline \multicolumn{7}{|l|}{ Orphanhood } \\
\hline \multicolumn{7}{|l|}{ Both living parents } \\
\hline Single orphan & 1.32 & $(0.72,2.41)$ & & & - & - \\
\hline Double orphan & 1.86 & $(0.73,4.76)$ & & & - & - \\
\hline \multicolumn{7}{|l|}{ Food insecure } \\
\hline No & Ref & & & & & \\
\hline Yes & 1.00 & $(0.93,1.06)$ & & & & \\
\hline \multicolumn{7}{|l|}{ Unstable housing } \\
\hline No & Ref & & & & Ref & \\
\hline Yes & $4.65^{* *}$ & $(1.80,11.99)$ & & & $7.11 * * *$ & $(2.74,18.47)$ \\
\hline \multicolumn{7}{|l|}{ Savings } \\
\hline Have savings & Ref & & & & & \\
\hline No savings & 0.52 & $(0.22,1.24)$ & & & - & - \\
\hline \multicolumn{7}{|l|}{ Employment } \\
\hline Employed & Ref & & & & & \\
\hline Full-time student & 1.73 & $(0.63,4.73)$ & & & - & - \\
\hline Unemployed & 2.26 & $(0.95,5.42)$ & & & - & - \\
\hline \multicolumn{7}{|c|}{ Household Socioeconomic Factors } \\
\hline \multicolumn{7}{|l|}{ Running water } \\
\hline Running water & Ref & & & & & \\
\hline No running water & 1.21 & $(0.58,2.52)$ & & & - & - \\
\hline \multicolumn{7}{|l|}{ Flooring } \\
\hline Cement/tile & Ref & & & & & \\
\hline Earth/sand & $0.50 *$ & $(0.23,0.88)$ & & & - & - \\
\hline \multicolumn{7}{|l|}{ Electricity } \\
\hline Electricity in home & Ref & & & & & \\
\hline No electricity & 1.21 & $(0.60,2.45)$ & & & - & - \\
\hline \multicolumn{7}{|l|}{ Assets } \\
\hline$\geq 3$ assets & Ref & & & & & \\
\hline$\leq 2$ assets & 1.59 & $(0.81,3.13)$ & & & - & - \\
\hline
\end{tabular}

Relationship characteristics

Age difference

$<10$ years

$\geq 10$ years older

Unknown partner age

Relationship type

Primary

Non-primary

\begin{tabular}{llll} 
Ref & & & \\
$3.28^{*}$ & $(1.07,10.06)$ & - & - \\
1.08 & $(0.36,3.20)$ & - & - \\
& & & \\
Ref & & Ref & \\
$4.42^{* * *}$ & $(2.48,7.88)$ & $4.06 * * *$ & $(2.37,6.94)$ \\
\hline
\end{tabular}


Table 3 (continued)

\begin{tabular}{|c|c|c|c|c|}
\hline \multicolumn{5}{|l|}{ Partner level } \\
\hline \multicolumn{5}{|l|}{ Children together } \\
\hline No & Ref & & Ref & \\
\hline Yes & $0.12 * * *$ & $(0.05,0.31)$ & $0.15^{* * *}$ & $(0.06,0.38)$ \\
\hline \multicolumn{5}{|l|}{ Partner concurrency } \\
\hline No other partner & Ref & & Ref & \\
\hline Has other partners/unknown & $1.73^{*}$ & $(1.02,2.94)$ & $1.85^{*}$ & $(1.11,3.08)$ \\
\hline \multicolumn{5}{|l|}{ Relationship length } \\
\hline$\geq 6$ months & Ref & & - & - \\
\hline 1 day & 1.14 & $(0.52,2.48)$ & - & - \\
\hline$<6$ months & $1.82 *$ & $(1.02,3.26)$ & - & - \\
\hline \multicolumn{5}{|l|}{ Couples HIV testing } \\
\hline Tested together & Ref & & & \\
\hline Not tested together & 1.04 & $(0.55,1.98)$ & - & - \\
\hline \multicolumn{5}{|c|}{ Fear physical violence if tested together } \\
\hline No/have tested as a couple & Ref & & Ref & \\
\hline Yes & 2.23 & $(0.75,6.60)$ & $2.81 *$ & $(1.26,6.29)$ \\
\hline \multicolumn{5}{|c|}{ Fear abandonment if tested together } \\
\hline No/have tested as a couple & Ref & & & \\
\hline Yes & 1.13 & $(0.45,2.84)$ & - & - \\
\hline
\end{tabular}

Adjusted for age and clinic

$* \mathrm{p}<.05, * * \mathrm{p}<.01, * * * \mathrm{p}<.001$

\section{Relationship-Level Factors Associated with Transactional Sex}

Transactional sex was more common with partners with certain characteristics. In bivariate models, odds of transactional sex were higher in the following relationships: $\geq 10$-year age difference, non-primary, shared children with partner, perceived to be in concurrent relationships, and short-term relationships ( $<6$ months and 1 day). Additionally, transactional sex was more common in relationships in which they had not received couple's HIV testing, and in those they feared physical violence or abandonment if they were to test together. Similar to Model 1, after adjusting for all relationship-level variables, age, and clinic, the effect sizes of variables found to be significant in bivariate analyses were attenuated (Model 2). Odds of transactional sex remained higher in relationships with partners who were: $\geq 10$ years older (AOR 3.28, 95\% CI 1.07, 10.06), non-primary (AOR 4.42, 95\% CI 2.48, 7.88 ), $<6$ months long (AOR 1.82, 95\% CI 1.02, 3.26), and those in which the female participant believed were in concurrent relationships (AOR 1.73, 95\% CI 1.02, 2.94) or they feared physical violence if they tested for HIV together (AOR $2.23,95 \%$ CI $0.75,6.60)$.

\section{Combined Individual and Relationship-Level Factors Associated with Transactional Sex}

The final model examined the combined effects of individual and relationship-level factors. Among individual-level factors, being divorced/widowed (AOR 5.07, 95\% CI 1.93, 13.25) and being unstably housed (AOR 7.11, 95\% CI 2.74, 18.47) were associated with increased odds of transactional sex. Being married was associated with reduced odds of transactional sex (AOR 0.26, 95\% CI 0.09, 0.72). At the relationship-level, non-primary relationship type (AOR 4.06, 95\% CI 2.37, 6.94), perceived partner concurrency (AOR 1.85, 95\% CI 1.11, 3.08), and fear of violence with testing (AOR 2.81, 95\% CI 1.26, 6.29), were associated with elevated odds of transactional sex. Having a child with the partner was protective against transactional sex (AOR 0.15, 95\% CI 0.06, 0.38).

\section{Discussion}

This study provides an in-depth analysis of transactional sexual relationships among AGYW in Malawi. We found that AGYW receive similar types of items from transactional versus non-transactional partners, however, they receive 
more money from transactional partners. In multivariable models, we found that at the individual-level being divorced or widowed, married, or unstably housed were robust correlates of transactional sex; at the relationship-level, AGYW had increased odds of transactional sex in relationships with: perceived partner concurrency, non-primary relationship status, and feared violence with couples HIV testing.

AGYW in the study received similar items and amounts of money from transactional versus non-transactional partners. We found that participants were primarily receiving lower valued items, however monetary values were quite high in contrast to general incomes in Malawi (\$27 per month) [30]. These findings align with previous research in Malawi highlighting the normative practice of gift giving and monetary support in adolescent and young adult relationships [31,6], and provides nuance by examining the range and value of what is provided. Our research contributes to a growing body of work exploring the value of exchanges in transactional partnerships [32-34]. Partnerships in which higher valued items are exchanged are viewed as riskier as they may put young women in situations where they may feel unable to refuse sex or negotiate condom use $[35,36]$.

AGYW who were divorced or widowed or unstably housed had high odds of engaging in transactional sex. Although these groups were a small subset of the sample (7\% divorce or widowed, and $7 \%$ unstably housed), they represent a population facing increased instability. Homelessness and unstable housing [37] have been previously linked to transactional sex among young adult populations, and in Malawi in particular [38], but there is limited exploration of the link between divorce/widowhood and transactional sex [39]. With limited opportunities for formal employment, AGYW who lose a long-term partner may be forced to look for economic support from transactional partners.

The findings on partner characteristics most strongly associated with transactional sex are consistent with previous work on this topic. Partner age-difference was highly associated with transactional sex, which is consistent with studies examining the characteristics of men reporting engaging in transactional sex with AGYW [17, 40, 41]. However, it is important to note that few relationships were confirmed to be with a partner 10 or more years older (intergenerational relationships) (5\%), though some of the relationships in which the partner age was unknown $(6 \%)$ may have been with a partner 10 or more years older. Furthermore, intergenerational relationships only accounted for $11 \%$ of all transactional sexual relationships that were recorded, which supports research refuting the notion that "sugar daddies" (older men who date younger women and provide large sums of money) are the primary type of transactional relationship [17]. While less common, transactional relationships with older partners may be among the riskiest because
HIV prevalence among men 25-29 (6.4\%) and 30-34 (9.2\%) in Malawi, is much higher than that of men of similar age to AGYW in the study (1\% among 15-24 year old men) [42].

Participants reported that they knew or suspected that over half of partners had other concurrent partners, and transactional sex was more common in these types of relationships. These findings corroborate evidence citing high levels of concurrency among men in Eastern and Southern Africa $[18,43]$. This is of particular concern as concurrency heightens AGYW's exposure to high risk sexual networks [18]. A study among men in South Africa found that men's non-primary partners tend to be younger than primary partners [18]. Given that HIV prevalence increases with age in Malawi [42], having partners whose concurrent partners are in older age groups can elevate AGYW's potential for acquiring HIV.

Transactional sex was more commonly reported in relationships in which AGYW feared their partner would be physically violent if they suggested couple's HIV testing. This finding is concerning for two reasons: (1) if AGYW fear violence resulting from HIV testing, then it is likely that they may be unable to negotiate other protective sexual behaviors with their partner; and (2) if the partner is unwilling to be tested as a couple, there is lower likelihood of mutual disclosure of HIV status in the relationship. Couples HIV testing is more protective against HIV compared to individual HIV testing because it increases condom use among serodiscordant couples [44]. Couples HIV testing may not be the most appropriate intervention for these types of relationships.

Our findings indicate that AGYW's social and structural vulnerabilities increase the likelihood of engagement in transactional sex in this setting. Structural approaches which have had some success in reducing transactional sex engagement include government cash transfers [45], providing tuition and uniforms to keep girls in school [46], and combination social protection approaches which combine cash transfers, free schooling, and parental monitoring [47]. In South Africa, the integration of government cash transfers, free schooling, and parental monitoring was associated with a 9\% reduction in transactional sex engagement among AGYW ages 12-18 [47]. However, it is possible that current effective structural approaches may miss some of the most vulnerable AGYW we identified through this research. AGYW who are divorced or widowed and those who are unstably housed may need additional supports including support in acquiring housing, larger cash transfers or vocational training. Research is needed to adapt current effective approaches to meet the unique needs of these vulnerable subpopulations.

Additionally, while efforts to address transactional sex have primarily focused on reducing structural vulnerabilities of young women, there is a critical need for approaches which address the behavior of transactional male partners. 
Gender transformative interventions which seek to change norms around sexual concurrency, intergenerational relationships, and HIV testing may help reduce women's vulnerability in transactional relationships [48]. Examples of such interventions include Stepping Stones and SASA which have shown reductions in key behaviors including, perpetration of intimate partner violence, transactional sex, condomless sex, and partner concurrency [49, 50].

There are a few limitations in this study. First, the crosssectional study design restricts our ability to infer causal relationships. However, these findings corroborate longitudinal evidence from this same cohort showing similar relationships between SES and transactional sex [51]. Despite the cross-sectional design, this study provides novel information about the role of individual and relationship characteristics in transactional sex engagement. The addition of relationship level factors highlights how transactional sex is shaped both by the characteristics of young women and the partners they are with. Second, there is the potential for information bias. Partner characteristics and behavior were self-reported and subject to recall bias which may have affected associations with transactional sex. To address recall bias, our analyses only focused on relationships within the past 6 months to ensure the most accurate capture of partner characteristics. Third, important factors which may impact engagement in transactional sex, such as family context [52], were not included in analyses. Fourth, the monetary and material support from partners may not be comprehensive of all support provided, and thus may obscure possible differences between transactional and non-transactional partners. Finally, this study sample was not recruited using nationally representative methods, thus findings may not be generalizable to all AGYW in Malawi.

\section{Conclusions}

AGYW vulnerability to acquiring HIV is determined, in large part, by their social and structural environment. Current research has primarily focused on the traits of AGYW, ignoring the relationship context. Our work shows that AGYW's individual socioeconomic circumstances lead to engagement in transactional relationships characterized by HIV risk. Social protection approaches which address multiple dimensions of SES are urgently needed for HIV prevention for this population.

Funding The study was funded by Evidence for HIV Prevention in Southern Africa (EHPSA), a DFID program managed by Mott MacDonald; National Institute of Mental Health [R00 MH104154]; and the National Institute of Allergy and Infectious Diseases [P30 AI50410].

Data Availability Not Applicable.

\section{Declarations}

Conflict of interest The authors declare that they have no conflict of interest.

Ethical Approval The study was approved by the University of North Carolina Institutional Review Board and Malawi National Health Sciences Research Committee.

Consent to Participate Written informed consent was obtained from all participants.

Consent for Publication Not Applicable.

Open Access This article is licensed under a Creative Commons Attribution 4.0 International License, which permits use, sharing, adaptation, distribution and reproduction in any medium or format, as long as you give appropriate credit to the original author(s) and the source, provide a link to the Creative Commons licence, and indicate if changes were made. The images or other third party material in this article are included in the article's Creative Commons licence, unless indicated otherwise in a credit line to the material. If material is not included in the article's Creative Commons licence and your intended use is not permitted by statutory regulation or exceeds the permitted use, you will need to obtain permission directly from the copyright holder. To view a copy of this licence, visit http://creativecommons.org/licenses/by/4.0/.

\section{References}

1. UNAIDS. Women and HIV: spotlight on adolescent girls and young women. Geneva: UNAIDS; 2019.

2. Stoebenau K, Heise L, Wamoyi J, et al. Revisiting the understanding of "transactional sex" in sub-Saharan Africa: a review and synthesis of the literature. Soc Sci Med. 2016;168:186-97.

3. Wamoyi J, Ranganathan M, Kyegombe N, et al. Improving the measurement of transactional sex in sub-Saharan Africa: a critical review. J Acquir Immune Defic Syndr. 2019;80:367.

4. Jewkes R, Dunkle K. Transactional sex and HIV incidence in a cohort of young women in the stepping stones trial. J AIDS Clin Res. 2012;3:158.

5. Kilburn K, Ranganathan M, Stoner MCD, et al. Transactional sex and incident HIV infection in a cohort of young women from rural South Africa. AIDS (London, England). 2018;32:1669-77.

6. Poulin M. Sex, money, and premarital partnerships in southern Malawi. Soc Sci Med. 2007;65:2383-93.

7. MacPherson EE, Sadalaki J, Njoloma M, et al. Transactional sex and HIV: understanding the gendered structural drivers of HIV in fishing communities in Southern Malawi. J Int AIDS Soc. 2012;15:17364.

8. Kamndaya M, Vearey J, Thomas L, Kabiru CW, Kazembe LN. The role of material deprivation and consumerism in the decisions to engage in transactional sex among young people in the urban slums of Blantyre, Malawi. Global Public Health. 2016;11(3):295-308.

9. Baird S, Özler B. Transactional Sex in Malawi. In: Shah M, Cunningham S, editors. The Oxford Handbook of the Economics of Prostitution. New York, NY: Oxford University Press; 2016.

10. Dunkle KL, Jewkes RK, Brown HC, et al. Transactional sex among women in Soweto, South Africa: prevalence, risk factors and association with HIV infection. Soc Sci Med. 2004;59:1581-92. 
11. Greif MJ. Housing, medical, and food deprivation in poor urban contexts: implications for multiple sexual partnerships and transactional sex in Nairobi's slums. Health Place. 2012;18:400-7.

12. Pascoe SJS, Langhaug LF, Mavhu W, et al. Poverty, food insufficiency and HIV infection and sexual behaviour among young rural Zimbabwean women. PLoS ONE. 2015;10:e0115290.

13. Weiser SD, Leiter K, Bangsberg DR, et al. Food insufficiency is associated with high-risk sexual behavior among women in Botswana and Swaziland. PLoS Med. 2007;4:e260.

14. Cluver L, Orkin M, Boyes M, et al. Transactional sex amongst AIDS-orphaned and AIDS-affected adolescents predicted by abuse and extreme poverty. J Acquir Immune Defic Syndr. 2011;58:336-43.

15. Kang M, Dunbar M, Laver S, et al. Maternal versus paternal orphans and HIV/STI risk among adolescent girls in Zimbabwe. AIDS Care. 2008;20:214-7.

16. Leclerc-Madlala S. Age-disparate and intergenerational sex in southern Africa: the dynamics of hypervulnerability. AIDS. 2008;22:S17-25.

17. Luke N. Confronting the 'sugar daddy' stereotype: age and economic asymmetries and risky sexual behavior in urban Kenya. Int Fam Plan Perspect. 2005;31:6-14.

18. Maughan-Brown B, Kenyon C, Lurie MN. Partner age differences and concurrency in South Africa: implications for HIV-infection risk among young women. AIDS Behav. 2014;18:2469-76.

19. Zembe YZ, Townsend L, Thorson A, et al. Intimate partner violence, relationship power inequity and the role of sexual and social risk factors in the production of violence among young women who have multiple sexual partners in a peri-urban setting in South Africa. PLoS ONE. 2015;10:e0139430.

20. Maganja RK, Maman S, Groves A, et al. Skinning the goat and pulling the load: transactional sex among youth in Dar es Salaam, Tanzania. AIDS Care. 2007;19:974-81.

21. Hawkins K, Price N, Mussa F. Milking the cow: young women's construction of identity and risk in age-disparate transactional sexual relationships in Maputo, Mozambique. Glob Public Health. 2009;4:169-82.

22. Diez Roux AV, Aiello AE. Multilevel analysis of infectious diseases. J Infect Dis. 2005; 191:S25-33.

23. Newcomb ME, Ryan DT, Garofalo R, et al. The effects of sexual partnership and relationship characteristics on three sexual risk variables in young men who have sex with men. Arch Sex Behav. 2014;43:61-72.

24. Zea MC, Reisen CA, Poppen PJ, et al. Unprotected anal intercourse among immigrant Latino MSM: the role of characteristics of the person and the sexual encounter. AIDS Behav. 2009;13:700-15.

25. Mustanski B, Starks T, Newcomb ME. Methods for the design and analysis of relationship and partner effects on sexual health. Arch Sex Behav. 2014;43:21-33.

26. Rosenberg NE, Bhushan NL, Vansia D, et al. Comparing youthfriendly health services to the standard of care through "girl power-Malawi": a quasi-experimental cohort study. J Acquir Immune Defic Syndr. 2018;79:458-66.

27. Rosenberg NE, Gichane MW, Vansia D, et al. Assessing the impact of a small-group behavioral intervention on sexual behaviors among adolescent girls and young women in Lilongwe Malawi: a Quasi-experimental cohort study. AIDS Behav. 2019;24:1542-50.

28. Rosenberg NE, Pettifor AE, Myers L, et al. Comparing four service delivery models for adolescent girls and young women through the 'Girl Power'study: protocol for a multisite quasiexperimental cohort study. BMJ Open. 2017;7:e018480.

29. UNAIDS. Transactional sex and HIV risk: from analysis to action. Geneva: UNAIDS; 2018.
30. World Bank. GNI per capita, Atlas method (current US\$)Malawi. Available at : https://data.worldbank.org/indicator/NY. GNP.PCAP.CD?locations=MW. Accessed 26 June 2019.

31. Moore AM, Biddlecom AE, Zulu EM. Prevalence and meanings of exchange of money or gifts for sex in unmarried adolescent sexual relationships in sub-Saharan Africa. Afr J Reprod Health. 2007;11:44-61.

32. Fielding-Miller R, Dunkle KL, Cooper HL, et al. Cultural consensus modeling to measure transactional sex in Swaziland: scale building and validation. Soc Sci Med. 2016;148:25-33.

33. Ranganathan M, Heise L, MacPhail C, et al. 'It's because I like things... it's a status and he buys me airtime': exploring the role of transactional sex in young women's consumption patterns in rural South Africa (secondary findings from HPTN 068). Reprod Health. 2018;15:102.

34. Luke N, Goldberg RE, Mberu BU, et al. Social exchange and sexual behavior in young women's premarital relationships in Kenya. J Marriage Fam. 2011;73:1048-64.

35. Ranganathan M, Heise L, MacPhail C, et al. "It's because I like things... it's a status and he buys me airtime": exploring the role of transactional sex in young women's consumption patterns in rural South Africa (secondary findings from HPTN 068). Reprod Health. 2018;15:102.

36. Kyegombe N, Meiksin R, Namakula S, et al. Community perspectives on the extent to which transactional sex is viewed as sexual exploitation in Central Uganda. BMC Int Health Hum Rights. 2020;20:1-16.

37. Greene JM, Ennett ST, Ringwalt CL. Prevalence and correlates of survival sex among runaway and homeless youth. Am J Public Health. 1999;89:1406-9.

38. Kamndaya M, Vearey J, Thomas L, et al. The role of material deprivation and consumerism in the decisions to engage in transactional sex among young people in the urban slums of Blantyre, Malawi. Glob Public Health. 2016;11:295-308.

39. Choudhry V, Ambresin AE, Nyakato VN, et al. Transactional sex and HIV risks-evidence from a cross-sectional national survey among young people in Uganda. Glob Health Action. 2015;8:27249.

40. Jewkes R, Morrell R, Sikweyiya Y, et al. Transactional relationships and sex with a woman in prostitution: prevalence and patterns in a representative sample of South African men. BMC Public Health. 2012;12:325.

41. Maughan-Brown B, Evans M, George G. Sexual behaviour of men and women within age-disparate partnerships in South Africa: implications for young women's HIV risk. PLoS ONE. 2016;11:e0159162.

42. National Statistical Office (NSO) [Malawi], ICF. Malawi Demographic and Health Survey 2015-16. Zomba, Malawi and Rockville, Maryland, USA; NSO, ICF; 2017.

43. Westercamp N, Mattson CL, Bailey RC. Measuring prevalence and correlates of concurrent sexual partnerships among young sexually active men in Kisumu, Kenya. AIDS Behav. 2013;17:3124-32.

44. Rosenberg NE, Hauser BM, Ryan J, et al. The effect of HIV counselling and testing on HIV acquisition in sub-Saharan Africa: a systematic review. Sex Transm Infect. 2016;92:579-86.

45. Cluver L, Boyes M, Orkin M, et al. Child-focused state cash transfers and adolescent risk of HIV infection in South Africa: a propensity-score-matched case-control study. Lancet Glob Health. 2013;1:e362-70.

46. Cho H, Mbai I, Luseno WK, et al. School support as structural HIV prevention for adolescent orphans in western Kenya. J Adolesc Health. 2018;62:44-51.

47. Cluver LD, Orkin FM, Yakubovich AR, et al. Combination social protection for reducing HIV-risk behavior among adolescents in South Africa. J Acquir Immune Defic Syndr. 2016;72:96-104. 
48. Dworkin SL, Treves-Kagan S, Lippman SA. Gender-transformative interventions to reduce HIV risks and violence with heterosexually-active men: a review of the global evidence. AIDS Behav. 2013; 17:2845-63.

49. Jewkes R, Nduna M, Levin J, et al. Impact of stepping stones on incidence of HIV and HSV-2 and sexual behaviour in rural South Africa: cluster randomised controlled trial. BMJ. 2008;337:a506.

50. Kyegombe N, Abramsky T, Devries KM, et al. The impact of SASA!, a community mobilization intervention, on reported HIVrelated risk behaviours and relationship dynamics in Kampala, Uganda. J Int AIDS Soc. 2014;17:19232.
51. Gichane MW, Moracco KE, Pettifor AE, et al. Socioeconomic predictors of transactional sex in a cohort of adolescent girls and young women in Malawi: a longitudinal analysis. AIDS Behav. 2020;24:3376-84.

52. Ajayi AI, Somefun OD. Transactional sex among Nigerian university students: the role of family structure and family support. PLoS ONE. 2019;14:e0210349.

Publisher's Note Springer Nature remains neutral with regard to jurisdictional claims in published maps and institutional affiliations. 